12,13

\title{
Почему наночастицы магнетит/золото со структурой ядро-оболочка недостаточно хороши и как их улучшить
}

\author{
(C) А.Э. Соколов ${ }^{1,2}$, О.С. Иванова ${ }^{1,2}$, А.С. Федоров ${ }^{1-3}$, Е.А. Ковалева ${ }^{3}$, М.А. Высотин ${ }^{1,2}$, \\ C.-R. Lin $^{4}$, C.Г. Овчинников ${ }^{1,2}$ \\ ${ }^{1}$ Институт ффизики им. Л.В. Киренского СО РАН, ФИЦ КНЦ СО РАН, \\ Красноярск, Россия \\ ${ }^{2}$ Сибирский фредеральный университет, \\ Красноярск, Россия \\ ${ }^{3}$ Томский государственный университет, \\ Томск, Россия \\ ${ }^{4}$ National Pingtung University, Pingtung City, \\ Pingtung County 90003, Taiwan \\ E-mail: sgo@iph.krasn.ru
}

Поступила в Редакцию 9 апреля 2021 г.

В окончательной редакции 9 апреля 2021 г.

Принята к публикации 19 апреля 2021 г.

\begin{abstract}
Проведены исследования природы образования химической связи на границе раздела магнетит/золото. B рамках DFT-GGA-расчетов исследованы геометрическая структура, электронные и магнитные свойства плоских слоев, состоящих из магнетита $\mathrm{Fe}_{3} \mathrm{O}_{4}$ и золота. Установлено, что удельная энергия и параметр смачивания границы раздела магнетит-золото отрицательны, что и приводит к островковому росту небольших частиц $\mathrm{Au}$ на поверхности $\mathrm{Fe}_{3} \mathrm{O}_{4}$. Рассмотрена роль промежуточного тонкого слоя титана между магнетитом и золотом. Удельная энергия и параметр смачивания границ магнетит-титан (для тонких слоев Ті) и магнетит-титан-золото положительны. Высказано предположение, что промежуточный тонкий слой титана на границе между поверхностью наночастицы магнетита и слоем золота позволит получать наночастицы магнетита, покрытые сплошным золотым покрытием.
\end{abstract}

Ключевые слова: магнитные наночастицы ядро-оболочка, граница раздела магнетит-золото, трехслойная структура магнетит-титан-золото.

DOI: 10.21883/FTT.2021.09.51312.19H

\section{1. Введение}

В последние годы очень широкое развитие получили исследования возможности использования магнитных наночастиц в биомедицине [1-8]: магнитная сепарация, адресная доставка лекарств, магнитная гипертермия, магнитомеханическая терапия, повышение контраста при МРТ и т.д. При этом использование магнитных наночастиц затрудняется их высокой склонностью к агрегации и быстрой биодеградацией в случае взаимодействия с биологическими системами, вследствие чего, магнитные наночастицы в терапевтических целях редко применяют в чистом виде. Обычно их инкапсулируют или помещают в биоинертные матрицы (различные органические соединения или полимеры, в том числе природного происхождения) с целью снижения возможного токсичного воздействия магнитной фазы, повышения её физико-химической устойчивости и создания возможности иммобилизации на поверхности таких капсул или матриц лекарственных препаратов [9].

В последнее время большое внимание уделяется изготовлению наноструктур ядро-оболочка, включающих магнитные оксиды железа, покрытые оболочкой из благородного металла (золото, платина, серебро и палладий [10-16]. Оболочка из золота придает дополнительные функциональные возможности, например для локального нагрева металлического слоя внешним излучением. Кроме того, такая оболочка уменышает токсичное действие магнитных наночастиц на организм. В качестве доказательства получения наночастиц со структурой ядро-оболочка авторами работ приводятся либо схемы [17], либо результаты электронной микроскопии, указывающие на увеличение размера наночастиц [18-20] в ходе химической реакции, или данные рентгеновской дифракции, показывающие доминирование пиков кристаллического золота при увеличении толщины поверхностного слоя золота [21]. При более внимательном анализе, ряд авторов приходит к выводу о наличии не сплошного покрытия наночастиц магнетита золотом, а скорее „декорирования“ более крупной наночастицы мелкими островками [16,22-24]. Аналогичная ситуация наблюдается и при синтезе наночастиц ядрооболочка, где в качестве покрытия выступает серебро. Нами в работе [23] тоже было показано декорирование наночастиц магнетита серебром, при создании наночастиц ядро-оболочка. Примеры декорированных структур показаны на рис. 1,2. 


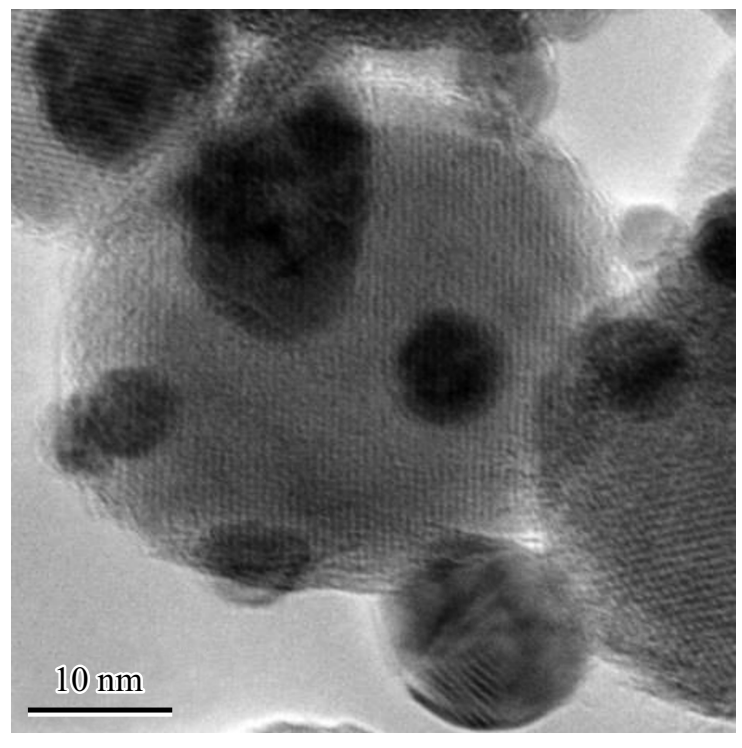

Pис. 1. Декорированные наночастицы $\mathrm{Fe}_{3} \mathrm{O}_{4} \mathrm{CAg}[23]$.
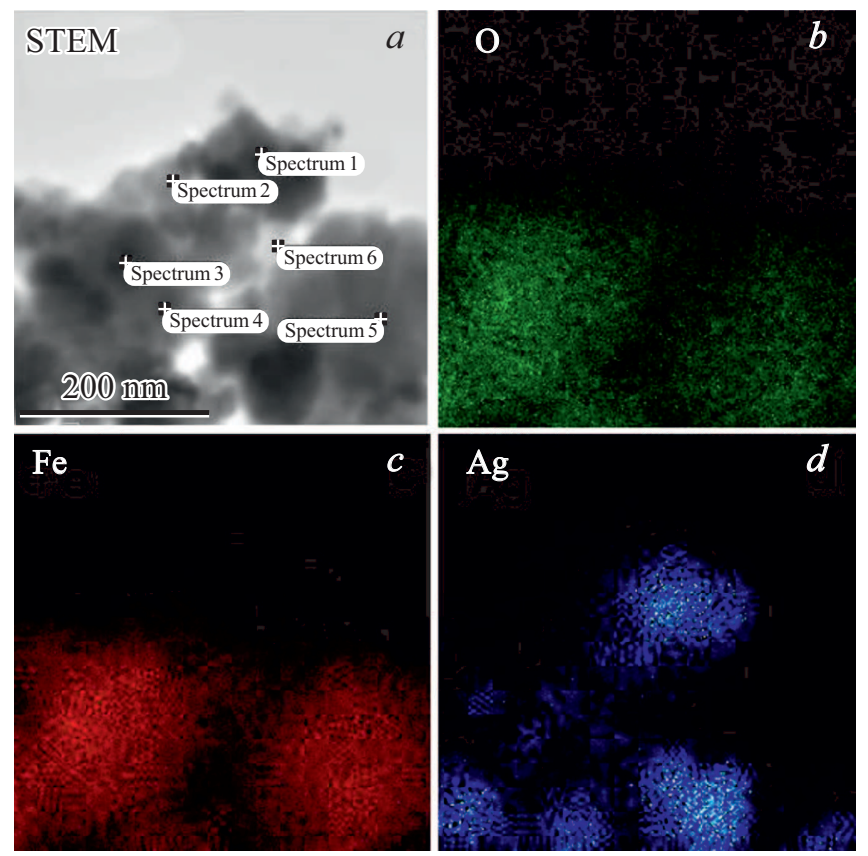

Рис. 2. Электронно-микроскопическое изображение и распределение элементов на наночастицах $\mathrm{Fe}_{3} \mathrm{O}_{4} \mathrm{CAg}$ по данным EDS-анализа. (Подробная характеризация данных наночастиц выполнена в нашей работе [23]).

В настоящей работе мы пытаемся понять, что является причиной островкового роста мелких наночастиц золота на поверхности магнетита. Возможно, эта причина связана с фундаментальными особенностями формирования химической связи в подобных системах? Поэтому в рамках теории функционала плотности мы исследовали особенности формирования химической связи между слоями магнетита и золота.

\section{2. Методика расчета}

Вместо искривленных поверхностей наночастиц мы исследовали планарную структуру из тонких слоев (слабов) $\mathrm{Fe}_{3} \mathrm{O}_{4}$ и $\mathrm{Au}$. Расчеты проводились в спинполяризованной версии теории функционала плотности в приближении GGA-PBE для обменно-корреляционного потенциала $[25,26]$ в рамках пакета VASP 5.4 [27,28]. При описании взаимодействия между слабами учитывалась поправка Гримме [29]. Для учета корреляционных эффектов использовалась поправка LDA $+U$ в виде, предложенном в работе [30] с параметром $U=4.0 \mathrm{eV}$ для атомов Fe. Расчет полной энергии структуры при оптимизации геометрии проводился до тех пор, пока остаточные силы, действующие на атомы, не становились менее $0.05 \mathrm{eV} / \AA$. Параметр обрезания по энергии был равен $500 \mathrm{eV}$ для всех расчетов.

Поскольку влияние температуры на параметры решетки достаточно мало и при нормальных условиях $(T \sim 300 \mathrm{~K})$ межатомные расстояния меняются на величину не превышающею $1 \%$ от значений при $T=0$, ввиду того что средние значения коэффициента линейного расширения твердых тел по порядку величины $\sim 10^{-5} \mathrm{~K}^{-1}$. Квантово-Химические расчеты проведены нами для $T=0$.

Сначала нами были рассчитаны объемные структуры золота и магнетита, для которых полученные параметры решетки хорошо согласуются с экспериментальными данными. Затем поверхности $\mathrm{Fe}_{3} \mathrm{O}_{4}(111)$ и $\mathrm{Au}(111)$ были сконструированы (рис. 3) как и в работах [31,32], где рассчитывалась оптимальные параметры поверхности магнетита. Вакуумный интервал $10 \AA$ между слабами устранял искусственное взаимодействие за счет периодических граничных условий в перпендикулярном интерфейсу направлении. Первая зона Бриллюэна согласно процедуре Монхорста-Пака [33] разбивалась на наборы $k$-точек $6 \times 6 \times 6$ и $12 \times 12 \times 12$ для объемных материалов и $6 \times 6 \times 1$ для всех слабов и интерфейсов [34].

Удельная поверхностная энергия $E_{s u r f}$ отдельного слаба $\mathrm{Fe}_{3} \mathrm{O}_{4}$ и $\mathrm{Au}$ вычислялась по формуле

$$
E_{\text {surf }}=\frac{E_{\text {slab }}-E_{\text {bulk }} N_{\text {slab }} / N_{\text {bulk }}}{2 A},
$$

где $E_{\text {bulk }}$ и $E_{\text {slab }}$ соответствуют полной энергии объемного образца и слаба с числом атомов $N_{\text {bulk }}$ и $N_{\text {slab }}$, соответственно, $A$ - площадь поверхности слаба. Слой магнетита задавался толщиной 12 монослоев, а толщина слоя золота варьировалась от 1 до 9 монослоев. В табл. 1 приведены значения поверхностной энергии, полученные для различного числа монослоев золота. Полученные данные позволяют сделать вывод, что 5 монослоев золота достаточно для надежного вычисления удельной поверхностной энергии $E_{s u r f}$.

Зная энергии отдельных слабов, полную энергию гибридной структуры магнетит/золото и удельную энергию поверхности, можно найти удельную энергию ин- 

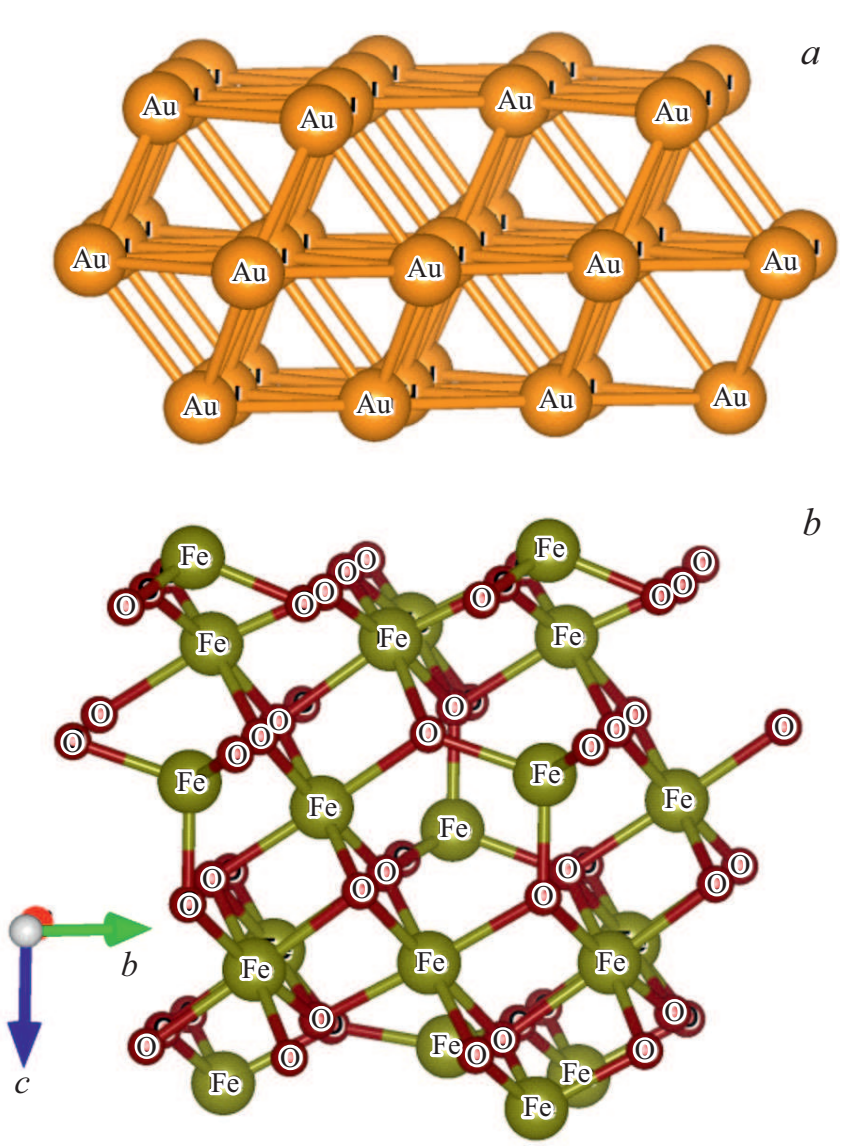

Рис. 3. Структура слоя магнетита $(b)$ и золота $(a)$, участвующие в расчетах. Атомы железа обозначены зеленым, кислорода - красным, золота - оранжевым цветом. (Рис. в цвете см. в эл. версии журнала).

Таблица 1. Значения поверхностной энергии слабов магнетита и золота для различного числа слоев золота на магнетите

\begin{tabular}{c|c|c}
\hline $\mathrm{Slab}$ & $N_{\text {layers }}$ & $E_{\text {surf }}, \mathrm{J} / \mathrm{m}^{2}$ \\
\hline $\mathrm{Fe}_{3} \mathrm{O}_{4}$ & 12 & 1.13 \\
$\mathrm{Au}$ & 1 & 1.00 \\
$\mathrm{Au}$ & 3 & 1.41 \\
$\mathrm{Au}$ & 5 & 1.40 \\
$\mathrm{Au}$ & 9 & 1.43
\end{tabular}

терфейса между слоями 1 и $2\left(E_{\text {int } 1,2}\right)$

$$
A \cdot E_{\text {int } 1,2}=\sum_{i=1,2}\left(E_{\text {slabi }}-A \cdot E_{\text {surfi }}\right)-E_{\text {hybrid } 1,2} .
$$

Параметр смачивания $S$, показывающий изменение полной энергии при распределении капли жидкого золота по поверхности подложки магнетита, определен по формуле

$$
S_{1,2}=\frac{E_{\text {slab } 1}+E_{\text {bulk } 2} \cdot N_{\text {slab } 2 / N_{\text {bulk } 2}-E_{\text {hybrid } 1,2}}}{A},
$$

где $S_{1,2}$ - параметр смачивания подложки 1 (магнетит) каплей 2 (золото).

\section{3. Результаты расчетов}

В табл. 2 приведены полученные значения энергий интерфейса и параметра смачивания для структуры магнетит/золото при различных числах атомных слоев золота от 1 до 9. Видно, что для всех толщин золота эти параметры отрицательны. Таким образом, интерфейс $\mathrm{Fe}_{3} \mathrm{O}_{4} / \mathrm{Au}$ с однородной границей раздела неустойчив, что и объясняет островковый рост маленьких частиц золота на поверхности большой частицы магнетита. В работе [35] показано, что в обратном случае, при осаждении магнетита на большую $(200 \mathrm{~nm})$ наночастицу золота, также формируются мелкие островки магнетита. Из табл. 2 также видно, что влияние золота на намагниченность частиц $\mathrm{Fe}_{3} \mathrm{O}_{4} @ \mathrm{Au}$ ничтожно.

Для стабилизации структуры интерфейса $\mathrm{Fe}_{3} \mathrm{O}_{4} / \mathrm{Au}$ мы предлагаем ввести дополнительный тонкий слой, который может сформировать устойчивый интерфейс как с магнетитом, так и с золотом. Такими свойствами обладает, например, слой титана. Рассчитанные по формулам (1)-(3) энергии интерфейса и параметры смачивания для $\mathrm{Fe}_{3} \mathrm{O}_{4} / \mathrm{Ti}, \mathrm{Ti} / \mathrm{Au}$ оказались положительны. На рис. 4 показано изменение геометрии слоя магнетита при контакте с титаном. Атомы кислорода, спрятанные в магнетите под поверхностью (рис. 3), при введении промежуточного слоя титана выходят на поверхность (рис. 4). Такая реконструкция поверхности обеспечивает стабильность однородного интерфейса $\mathrm{Fe}_{3} \mathrm{O}_{4} / \mathrm{Ti}$.

При осаждении золота интерфейс $\mathrm{Fe}_{3} \mathrm{O}_{4} / \mathrm{Ti}$ действует как новая комплексная подложка, поэтому параметр

Таблица 2. Удельная энергия интерфейса, параметр смачивания, кратчайшее расстояние между атомами $\mathrm{Fe}$ и Аu, и намагниченность на ячейку (4 формульные единицы) слаба магнетит/золото с разными числами монослоев золота

\begin{tabular}{c|c|c|c|c}
\hline Interface & $E_{\text {int } 1,2}, \mathrm{~J} / \mathrm{m}^{2}$ & $S_{1,2}, \mathrm{~J} / \mathrm{m}^{2}$ & $d_{\mathrm{Fe}-\mathrm{Au}}, \AA$ & Magnetization, $\mu_{B}$ \\
\hline $\mathrm{Fe}_{3} \mathrm{O}_{4} / 1 \mathrm{Au}$ & -0.92 & -0.70 & 2.72 & 18.50 \\
$\mathrm{Fe}_{3} \mathrm{O}_{4} / 3 \mathrm{Au}$ & -1.32 & -1.49 & 2.78 & 18.61 \\
$\mathrm{Fe}_{3} \mathrm{O}_{4} / 5 \mathrm{Au}$ & -1.40 & -1.54 & 2.77 & 18.41 \\
$\mathrm{Fe}_{3} \mathrm{O}_{4} / 9 \mathrm{Au}$ & -1.47 & -1.63 & 2.59 & 18.86
\end{tabular}




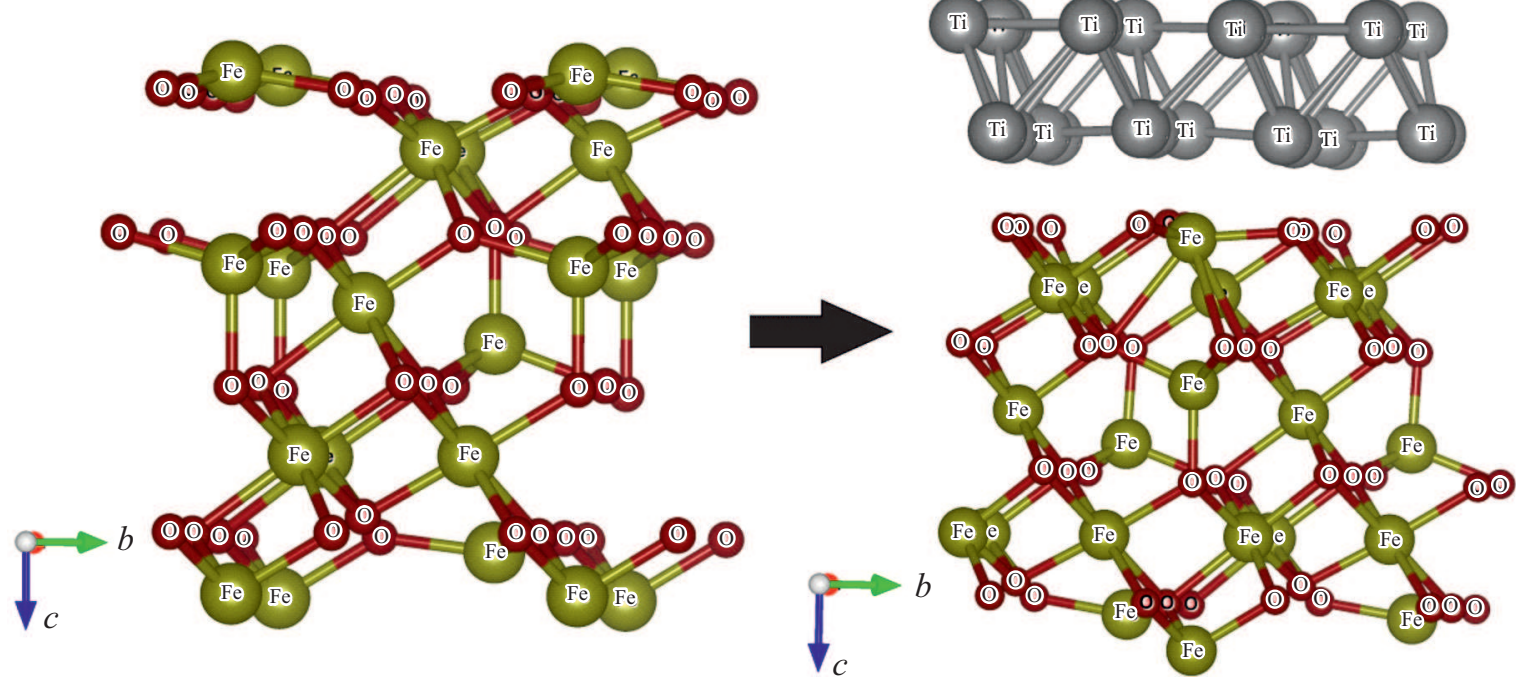

Рис. 4. Модификация поверхности магнетита при введении промежуточного слоя титана. Атомы железа обозначены зеленым, кислорода - красным, титана - серым цветом. (Рис. в цвете см. в эл. версии журнала).

смачивания его с Аu вычисляется по модифицированной формуле типа (3)

$$
S_{2,3}=\frac{E_{\text {hybrid } 1,2}+E_{\text {bulk } 3} \cdot N_{\text {slab } 3} / N_{\text {bulk } 3}-E_{\text {hybrid } 1,2,3}}{A},
$$

где $S_{2,3}$ - параметр смачивания подложки 1 (магнетит) с уже нанесенным слоем 2 (титан) каплей 3 (золото). Удельная энергия интерфейса, параметр смачивания, кратчайшее расстояние между атомами $\mathrm{Fe}-\mathrm{Ti}$ и $\mathrm{Ti}-\mathrm{Au}$, и намагниченность на ячейку (4 формульные единицы) структуры магнетит/титан/золото с разными числами монослоев золота приведены в табл. 3. Наши расчеты для 5 и 9 монослоев Ті привели к отрицательному параметру смачивания -0.19 и $-0.61 \mathrm{~J} / \mathrm{m}^{2}$, соответственно, так что можно утверждать, что промежуточный слой титана должен быть действительно атомарной толщины.

Нами также изучены электронные и магнитные свойства всех исследованных слоистых структур. Анализ парциальных плотностей электронных состояний позволил установить, что слои магнетит-титан-золото являются проводящими за счет слоя золота, при этом существенных изменений магнитных моментов на атомах железа не происходит.

\section{4. Заключение}

В настоящей работе мы исследовали природу образования химической связи на границе раздела магнетит/золото и обнаружили, что промежуточный слой титана может стабилизировать структуру наночастиц со структурой магнитное ядро-золотая оболочка. В рамках DFT-GGA расчетов исследованы геометрическая структура, электронные и магнитные свойства плоских слоев, состоящих из магнетита $\mathrm{Fe}_{3} \mathrm{O}_{4}$, титана и золота.

Полные и удельные поверхностные энергии изолированных пластин магнетита, титана и золота, а также двухслойных и трехслойных слоев, образованных путем их поверхностного контакта, удельные энергии границ раздела и параметры смачивания рассчитаны для границы магнетит/золото, магнетит/титан и титан/золото. Установлено, что удельная энергия и параметр смачивания границы раздела магнетит/золото отрицательны, в то время как эти значения для границы магнетит/титан (для тонких слоев Ті) и границы раздела магнетиттитан/золото положительны. Это позволяет надеяться, что промежуточный тонкий слой титана на границе между поверхностью наночастицы магнетита и слоем золота стабилизирует эту трехслойную структуру и

Таблица 3. Удельная энергия интерфейса, параметр смачивания, кратчайшее расстояние между атомами Fe-Ti и Ti-Au, и намагниченность слаба магнетит/титан/золото с разными числами монослоев золота

\begin{tabular}{c|c|c|c|c|c}
\hline Interface & $E_{\text {int }}, \mathrm{J} / \mathrm{m}^{2}$ & $S, \mathrm{~J} / \mathrm{m}^{2}$ & $d_{\mathrm{Fe}-\mathrm{Ti}}, \AA$ & $d_{\mathrm{Ti}-\mathrm{Au}}, \AA$ & Magnetization, $\mu_{B}$ \\
\hline $\mathrm{Fe}_{3} \mathrm{O}_{4} / 2 \mathrm{Ti}$ & 1.23 & 0.13 & 2.73 & & 17.62 \\
$\mathrm{Fe}_{3} \mathrm{O}_{4} / 2 \mathrm{Ti} / 1 \mathrm{Au}$ & 0.75 & 2.08 & 2.72 & 2.73 & 17.92 \\
$\mathrm{Fe}_{3} \mathrm{O}_{4} / 2 \mathrm{Ti} / 3 \mathrm{Au}$ & 0.88 & 1.82 & 2.73 & 2.74 & 18.00 \\
$\mathrm{Fe}_{3} \mathrm{O}_{4} / 2 \mathrm{Ti} / 5 \mathrm{Au}$ & 0.82 & 1.79 & 2.75 & 2.74 & 17.87 \\
$\mathrm{Fe}_{3} \mathrm{O}_{4} / 2 \mathrm{Ti} / 9 \mathrm{Au}$ & 0.80 & 1.74 & 2.73 & 2.73 & 17.91
\end{tabular}


позволит получать наночастицы магнетита, покрытые сплошным золотым покрытием.

Изучены также электронные и магнитные свойства всех исследованных слоистых структур. Анализируя парциальную плотность электронных состояний, было установлено, что слои магнетит/титан/золото являются проводящими за счет слоя золота, при этом существенных изменений магнитных моментов на атомах железа не происходит. В целом расчеты показывают, что буферный титановый слой стабилизирует пластины магнетит/титан/золото, что должно способствовать синтезу наночастиц магнитного магнетита, покрытых золотом.

На основе проведенных исследований можно дать некоторый качественный рецепт, когда и какая прослойка может быть использована для решения вопроса о смачиваемости. В данном случае золото не образует оксида - поэтому отсутствует сплошное покрытие оксида железа оболочкой из золота. Титан, наоборот, образует оксид и поэтому легко образует моноатомную оболочку. Можно сказать, что на поверхность оксида нужно всегда сначала нанести окисляемый слой, а потом добавлять слой золота. Хотя возможны и комбинации, когда неокисляемый элемент имеет хорошую адгезию на поверхности другого оксида.

\section{Финансирование работы}

Авторы благодарят совместный грант РФФИ 19-5252002 и инистерства науки и технологий Тайваня MOST \# 109-2112-M-153-003 и \# 108-2923-M-153-001-MY3 за финансовую поддержку.

\section{Конфликт интересов}

Авторы заявляют, что у них нет конфликта интересов.

\section{Список литературы}

[1] В.Н. Никифоров. Изв. Академии инженерных наук им. А.М. Прохорова 1, 23 (2013).

[2] A. Doaga, A.M. Cojocariu, C.P. Constantin, R. Hempelmann, O.F. Caltun. AIP Conf. Proc. 1564, 1, 123 (2013).

[3] N. Tran, T.J. Webster. J. Mater. Chem. 20, 40, 8760 (2010).

[4] V.F. Cardoso, A. Francesko, C. Ribeiro, M. Bañobre-López, P. Martins, S. Lanceros-Mendez. Adv. Healthcare Mater. 7, 5, 1700845 (2018).

[5] M. Mahdavi, M.B. Ahmad, M.J. Haron, F. Namvar, B. Nadi, M.Z. Ab Rahman. J. Amin. Mol. 18, 7, 7533 (2013).

[6] J. Gao, H. Gu, B. Xu. Accounts Chem. Res. 42, 8, 1097 (2009).

[7] C. Sun, J.S.H. Lee, M. Zhang. Adv. Drug Deliv. Rev. 60, 11, $1252(2008)$.

[8] P. Tartaj, M. Del Puerto Morales, S. Veintemillas-Verdaguer, T. González-Carreño, C.J. Serna. J. Phys. D 36, 13, R182 (2003).

[9] K. Chatterjee, S. Sarkar, K. Jagajjanani Rao, S. Paria. Adv. Colloid Interface Sci. 209, 8 (2014).
[10] S. Laurent, D. Forge, M. Port, A. Roch, C. Robic, L. Vander Elst, R.N. Muller. Chem. Rev. 108, 6, 2064 (2008).

[11] S. Venkateswarlu, B. Natesh Kumar, B. Prathima, K. Anitha, N.V.V. Jyothi. Physica B 457, 30 (2015).

[12] Z. Wang, B. Shen, Z. Aihua, N. He. Chem. Eng. J. 113, 1, 27 (2005).

[13] A. Bachhuka, S.N. Christo, A. Cavallaro, K.R. Diener, A. Mierczynska, L.E. Smith, R. Marian, J. Manavis, J.D. Hayball, K. Vasilev. Adv. Colloid Interface Sci 457, 9 (2015).

[14] П.Д. Рудаковская, Е.К. Белоглазкина, А.Г. Мажуга, Н.Л. Клячко, А.В. Кабанов, Н.В. Зык. Вестн. МГУ. Сер. 2. Химия 56, 3, 181 (2015).

[15] А.Ю. Соловьева, Ю.В. Иони, А.О. Баскаков, С.С. Старчиков, А.С. Авилов, И.С. Любутин, С.П. Губин. Журн. неорган. химии 62, 6, 725 (2017).

[16] M.V. Efremova, Yu.A. Nalench, E. Myrovali, A.S. Garanina, I.S. Grebennikov, P.K. Gifer, M.A. Abakumov, M. Spasova, M. Angelakeris, A.G. Savchenko, M. Farle, N. Klyachko, A. Majouga, U. Wiedwald. Beilstein J. Nanotechnology 9, 2684 (2018).

[17] A.M. El-Toni, M.A. Habila, J.P. Labis, Z.A. Alothman, M. Alhoshan, A.A. Elzatahry, F. Zhang. Nanoscale 8, 5, 2510 (2016).

[18] L. Wang, J. Luo, Q. Fan, M. Suzuki, I.S. Suzuki, M.H. Engelhard, Yu. Lin, N. Kim, J.Q. Wang, Chuan-Jian Zhong. J. Phys. Chem. B 109, 46, 21593 (2005).

[19] H.Y. Park, M.J. Schadt, L. Wang, I-Im.S. Lim, P.N. Njoki, S.H. Kim, M.Y. Jang, J. Luo, C.J. Zhong. Langmuir 23, 17, 9050 (2007).

[20] U. Tamer, Y. Gundogdu, I.H. Boyaci, K. Pekmez. J. Nanoparticle Res. 12, 4, 1187 (2010).

[21] Z. Xu, Y. Hou, S. Sun. J. Am. Chem. Soc. 129, 28, 8698 (2007).

[22] H. Maleki, A. Simchi, M. Imani, B.F.O. Costa. J. Magn. Magn. Mater. 324, 23, 3997 (2012).

[23] D.A. Petrov, C.-R. Lin, R.D. Ivantsov, S.G. Ovchinnikov, S.M. Zharkov, G.Y. Yurkin, D.A. Velikanov, Y.V. Knyazev, M.S. Molokeev, Y.-T. Tseng, E.-S. Lin, I.S. Edelman, A.O. Baskakov, S.S. Starchikov, I.S. Lyubutin. Nanotechnology 31, 395703 (2020).

[24] С.В. Сайкова, Т.В. Трофимова, А.Ю. Павликов, Д.В. Карпов, Д.И. Чистяков, Ю.Л. Михлин. Изв. РАН. Сер. хим. 7, 1284 (2020).

[25] P.E. Blöchl. Phys. Rev. B 50, 17953 (1994).

[26] G. Kresse, D. Joubert. Phys. Rev. B 59, 3, 1758 (1999).

[27] G. Kresse, J. Furthmuller. Comput. Mater. Sci. 6, 1, 15 (1996).

[28] G. Kresse, J. Furthmuller. Phys. Rev. B 54, 16, 11169 (1996).

[29] S. Grimme, J. Antony, S. Ehrlich, H. Krieg. J. Chem. Phys. 132, 154104 (2010).

[30] S. Dudarev, G. Botton. Phys. Rev. B 57, 1505 (1998).

[31] J. Noh, O.I. Osman, S.G. Aziz, P. Winget, J.L. Bredas. Chem. Mater. 27, 5856 (2015).

[32] A. Kiejna, T. Pabisiak. Surface Sci. 679, 225 (2019).

[33] H.J. Monkhorst, J.D. Pack. Phys. Rev. B 13, 5188 (1976).

[34] A.S. Fedorov, E.A. Kovaleva, A.E. Sokolov, M.A. Vysotin, C.R. Lin, S.G. Ovchinniko. Submitted Mater. Chem. Phys. (2021).

[35] M. Torras, A. Gordillo, A. Roig. Rev. Soc. Catalana Química 17, 107 (2018).

Редактор К.В. Емцев 